\title{
The Crabtree Effect: A Regulatory System in Yeast
}

\author{
By R. H. De DEKEN \\ Institut de Recherches du C.E.R.I.A., Brussels, Belgium
}

(Received 19 October 1965)

\begin{abstract}
SUMMARY
When Saccharomyces cerevisiae is growing exponentially on glucose or fructose as carbon plus energy source, and in the presence of air, the glucose degradation proceeds mainly via aerobic fermentation. When the yeast is growing on mannose or galactose, degradation proceeds simultaneously via respiration and fermentation. This situation results from a repression of the of the respiratory enzymes synthesis by high fermentation rates. This regulatory system, called the 'Crabtree effect', consists actually of a repression of an energy source (respiration) by another energy source (fermentation). Various yeast strains were tested; the regulatory system was present in about $50 \%$ of them.
\end{abstract}

\section{INTRODUCTION}

For many years the 'Pasteur effect' was an important topic in biochemistry. The Pasteur effect is defined as an 'inhibition of the activity' of the fermentation pathway by respiration (see Slonimski, 1956). Recent work (Salas, Viñuela, Salas \& Sols, 1965) pointed out the existence of a feed-back inhibition of the phosphofructokinase by citrate. If this allosteric inhibition is really responsible for the Pasteur effect, it means that the Pasteur effect is an inhibition of the fermentation pathway by an end product of aerobic glucose utilization. Nevertheless, it is important to keep in mind that all the studies of the Pasteur effect were made with suspensions of organisms. In other words, we do not know whether the Pasteur effect plays any important role during growth. We know that under certain welldefined conditions, i.e. the exponential growth of Saccharomyces cerevisiae in the presence of a high concentration of glucose, the Pasteur effect does not have the opportunity to work, because under these conditions the degradation of glucose proceeds via fermentation only. This phenomenon is known as the 'contre-effet Pasteur' or 'Crabtree effect' (after Crabtree, 1929).

It was shown by Swanson \& Clifton (1948) for the first time that most of the aerobic growth of a yeast (Saccharomyces cerevisiae) on glucose proceeds via fermentation. A quantitative study of the aerobic growth of yeast made by Lemoigne, Aubert \& Millet (1954) showed a diauxic growth on high concentrations of glucose: a fast growth involving intensive aerobic fermentation, followed by a slow growth involving oxidation of the accumulated ethanol. At lower glucose concentrations $(5-10 \mathrm{mg} . / 100 \mathrm{ml}$.) the absence of any noticeable diauxie suggested that the pathway used for the degradation of glucose might depend on the glucose concentration.

Slonimski (1956) studied the rate of respiratory adaptation in Saccharomyces

Vol. 44, No. 1 was issued 11 August 1966 
cerevisiae as a function of the glucose concentration. At low concentrations of glucose (below $6 \times 10^{-3} \mathrm{M}$ ) the rate of respiratory adaptation increased as the concentration of glucose was increased. This relationship was to be expected since the aerobic fermentation of glucose proceeds very slowly at these glucose concentrations and severely limits the supply of energy to the organisms. But at concentrations of glucose higher than $6 \times 10^{-3} \mathrm{M}$, the rate of adaptation to aerobic conditions decreased as the concentration of glucose was increased. Simultaneously, as the concentration of glucose increased, the rate of aerobic fermentation also increased. It is this inhibition of the synthesis of respiratory enzymes by the high fermentation rates which occur at high glucose concentrations which is known as the contre-effet Pasteur. Slonimski's work, which was done with suspensions of organisms, was followed by a more extensive study of the contre-effet Pasteur in a growing yeast (Ephrussi, Slonimski, Yotsuyanagi \& Tavlitzki, 1956). Starting a culture in the presence of $3 \%(\mathrm{w} / \mathrm{v})$ glucose with organisms fully adapted to aerobic conditions, the following was observed: the rate of aerobic fermentation $\left(Q_{\mathrm{Co}_{2}}\right.$ ferm. $)$ increased sharply during the phase of exponential growth; at the same time the rate of respiration $\left(\mathrm{Q}_{2}\right)$ decreased to a low value. A few generations before the end of the exponential phase the glucose no longer saturated the fermentation system, and as a result the $Q_{\mathrm{Co}_{2}}$ ferm. decreased to a low value; simultaneously the $Q_{\mathrm{o}_{2}}$ increased (respiratory adaptation). This experiment showed clearly that the contre-effet Pasteur is an important part of the physiology of a yeast like $\boldsymbol{S}$. cerevisiae growing in a high concentration of glucose.

In the following pages we shall use the term 'Crabtree effect' (Crabtree, 1929) rather than contre-effet Pasteur to define the 'inhibition of the synthesis' of the respiratory enzymes, in order to avoid confusion with the Pasteur effect, i.e. the 'inhibition of the fermentation activity' by respiration. The present work shows that under certain conditions the degradation of carbohydrates by an exponentially growing yeast may proceed through fermentation and respiration simultaneously. This situation occurs when mannose or galactose is used as carbon plus energy source instead of glucose, and seems to be the result of a partial but constant repression of the respiratory system. Several yeast strains belonging to different genera were tested for the Crabtree effect and about $50 \%$ of them showed the effect. Fermentation and oxidation of glucose were compared in two strains, one of which showed the Crabtree effect and the other not; the comparison showed that the fermentation pathway was largely constitutive for the strain which showed a strong Crabtree effect.

\section{METHODS}

Growth medium. The medium used contained $10 \cdot 9 \mathrm{~g} . \mathrm{KH}_{2} \mathrm{PO}_{4}, \mathbf{5} \cdot 0 \mathrm{~g}$. Difco yeast extract and $30.0 \mathrm{~g}$. hexose, made to $1000 \mathrm{ml}$. after adjusting to $\mathrm{pH} 6.5$ with potassium hydroxide.

Hexoses. Hexoses of bacteriological purity were obtained from S. T. Gurr (136 New Kings Road, London, S.W.6). Some batches of galactose had to be recrystallized in $80 \%$ ethanol in water to remove glucose. The galactose from Merck was purified by two or three recrystallizations. Glucose contamination was detected by growing the 'petite' mutant of Saccharomyces cerevisiae on the sugar : diauxic growth was easily detectable because the petite mutant grows faster on glucose than on galactose. 
Organisms. The strains of Saccharomyces cerevisiae used were diploid 'yeast foam' strains (normal and 'petite') originally from Dr B. Ephrussi's laboratory. Candida tropicalis IRC 121 was a strain isolated at the Institut de Recherches du C.E.R.I.A. All the other strains were obtained from collections.

Manometric determinations. To avoid modifications of the cell metabolism, the gas exchanges were measured directly in the culture, without centrifugation and resuspension. The manometric determinations were made on $2 \mathrm{ml}$. of culture containing $7 \times 10^{6}$ organisms $/ \mathrm{ml}$. Respiration (oxygen uptake) was measured in the presence of $0.3 \mathrm{ml}$. of a $20 \% \mathrm{KOH}$ solution spread over a large surface of filter paper. Aerobic fermentation was measured under the same conditions but without KOH. The $\mathrm{CO}_{2}$ evolved was considered to be the result of fermentation, assuming that the respiratory quotient $\left(Q_{\mathrm{Co}_{2}}: Q_{\mathrm{O}_{2}}\right)$ of the concomitant respiration was unity.

\section{RESULTS}

\section{Measurement of the limiting rates of fermentation of various hexoses}

Using the petite mutant of Saccharomyces cerevisiae (respiration deficient) it is possible to measure the limiting rates of aerobic degradation of different hexoses without complications due to respiration. Data are presented in Table 1 for glucose,

Table 1. Rates of fermentation and growth of Saccharomyces cerevisiae petite mutant on various hexoses

\begin{tabular}{|c|c|c|c|c|c|}
\hline \multirow[b]{2}{*}{$\begin{array}{c}\text { Carbon source } \\
(3 \mathrm{~g} . / 100 \mathrm{ml} .)\end{array}$} & \multirow{2}{*}{$\begin{array}{c}\text { Aerobic } \\
\text { fermentation } \\
\left(\mu \mathrm{l} . \mathrm{CO}_{2} / 10 \mathrm{~min} . /\right. \\
\left.10^{7} \text { organisms }\right)\end{array}$} & \multicolumn{2}{|c|}{ Growth rate } & \multirow{2}{*}{$\begin{array}{l}\text { Fermentation } \\
\text { rate (\% of } \\
\text { glucose value) }\end{array}$} & \multirow{2}{*}{$\begin{array}{c}\text { Growth rate } \\
\text { ( } \% \text { of } \\
\text { glucose value) }\end{array}$} \\
\hline & & $\begin{array}{l}\text { Generation } \\
\text { time (min.) }\end{array}$ & $\begin{array}{c}\text { Number of } \\
\text { doublings/hr. }\end{array}$ & & \\
\hline Glucose & $72 \cdot 4$ & 70 & 0.857 & $100 \cdot 0$ & $100 \cdot 0$ \\
\hline Fructose & $70 \cdot 6$ & 70 & $0 \cdot 857$ & $97 \cdot 5$ & $100 \cdot 0$ \\
\hline Mannose & $52 \cdot 0$ & 96 & 0.625 & 71.8 & $72 \cdot 9$ \\
\hline Galactose & $30 \cdot 0$ & 139 & $0 \cdot 432$ & $41 \cdot 4$ & $50 \cdot 4$ \\
\hline
\end{tabular}

fructose, mannose and galactose. Glucose and fructose had identical rates of fermentation. The rate that of degradation of mannose was somewhat lower $(71 \cdot 8 \%$ that of glucose) and that of galactose still lower $(41 \cdot 4 \%)$. The differences in growth rates of the petite mutant on these various sugars indicated that the rate of fermentation was the factor which limited growth. The rates of growth of the petite mutant on mannose and galactose were respectively $\mathbf{7 2 . 9} \%$ and $50.4 \%$ of the rate of growth on glucose, which is a clear and quantitative correlation between rate of fermentation and rate of growth.

\section{Behaviour of the normal strain of Saccharomyces cerevisiae in the presence of various hexoses; rates of respiration, fermentation and growth}

The results obtained with the petite mutant of Saccharomyces cerevisiae showed that the fermentation rates of mannose and galactose were slow and growthlimiting. The aim of the following experiment was to see whether a normal strain of $S$. cerevisiae was able to elaborate a respiratory system when mannose or galactose was the carbon plus energy source. Manometric determinations of the respiration and fermentation rates were made on growing cultures as described under Methods. The results are given in Table 2 . 
From a comparison of Tables 1 and 2 , one can conclude that the maximum rate of fermentation of each of the various sugars (with the exception of galactose) were the same for both the normal and the petite strains. In the case of galactose the fermentation rate was lower for the normal strain than for the petite: this situation resulted probably from an inhibition of the fermentation by the respiration (Pasteur effect).

The respiration rate was low when the normal strain grew on glucose or fructose. The rate was twice as high when the strain grew on mannose, and four times as high on galactose. In other words, this yeast was able to elaborate a respiratory system when the rate of fermentation was sufficiently low.

Table 2. Rates of fermentation, respiration and growth of Saccharomyces cerevisiae normal strain on various hexoses

\begin{tabular}{|c|c|c|c|c|c|c|c|}
\hline \multirow[b]{2}{*}{ Carbon source } & \multicolumn{2}{|c|}{$\begin{array}{c}\text { Rate of aerobic } \\
\text { fermentation }\end{array}$} & \multicolumn{2}{|c|}{$\begin{array}{l}\text { Rate of } \\
\text { respiration }\end{array}$} & \multicolumn{3}{|c|}{ Rate of growth } \\
\hline & $\begin{array}{c}\mu \mathrm{l.} \mathrm{CO}_{2} / 10 \\
\text { min./10? } \\
\text { organisms }\end{array}$ & $\begin{array}{c}\text { As \% of } \\
\text { glucose } \\
\text { value }\end{array}$ & $\begin{array}{c}\mu 1 . \mathrm{O}_{2} / 10 \\
\text { min./10? } \\
\text { organisms }\end{array}$ & $\begin{array}{c}\text { As } \% \text { of } \\
\text { glucose } \\
\text { value }\end{array}$ & $\begin{array}{c}\text { Genera- } \\
\text { tion } \\
\text { time } \\
\text { (min.) }\end{array}$ & $\begin{array}{c}\text { Number of } \\
\text { doublings } / \\
\text { hr. }\end{array}$ & $\begin{array}{c}\text { As } \% \text { of } \\
\text { glucose } \\
\text { value }\end{array}$ \\
\hline Glucose & $78 \cdot 0$ & $100 \cdot 0$ & $4 \cdot 8$ & $100 \cdot 0$ & 53 & $1 \cdot 13$ & $100 \cdot 0$ \\
\hline Fructose & $69 \cdot 0$ & $88 \cdot 4$ & $6 \cdot 1$ & $127 \cdot 0$ & 53 & $1 \cdot 13$ & $100 \cdot 0$ \\
\hline Mannose & $46 \cdot 0$ & $59 \cdot 0$ & $10 \cdot 6$ & $221 \cdot 0$ & 63 & 0.952 & $84 \cdot 0$ \\
\hline Galactose & $15 \cdot 3$ & $19 \cdot 6$ & $20 \cdot 0$ & $416 \cdot 0$ & 72 & 0.833 & $74 \cdot 0$ \\
\hline
\end{tabular}

NotE. These experiments were repeated in the presence of a higher concentration of hexoses: $6 \mathrm{~g} . / 100 \mathrm{ml}$. The results were the same as those obtained at $3 \mathrm{~g} . / 100 \mathrm{ml}$.

The growth rate of the petite mutant on mannose or galactose was slower than the growth rate on glucose (Table 1). This was not the case for the normal strain, with which the growth rates on mannose or galactose were close to the growth rate on glucose (Table 2). This means that the increased respiration rate compensated for an insufficient fermentation rate.

\section{Nature of the growth-limiting factor for Saccharomyces cerevisiae degrading a sugar by aerobic fermentation}

The good correlation that exists between growth rate and fermentation rate on various sugars with the petite mutant of $S$. cerevisiae indicates that the rate of fermentation is the growth-limiting factor. The nature of this limitation might be either the rate at which intermediary metabolites are made available to the cell, or the rate of energy production. If one compares a yeast strain which degrades glucose by aerobic fermentation, like $\boldsymbol{S}$. cerevisiae normal strain, with a strain which degrades glucose by respiration, like Candida tropicalis (an organism which has no Crabtree effect), one can eliminate the first possibility. Growing $S$. cerevisiae organisms have an aerobic fermentation rate of $78 \mu \mathrm{l} . \mathrm{CO}_{2} / 10 \mathrm{~min} . / 10^{7}$ organisms, which corresponds to a degradation rate of $1.74 \mu$ moles glucose $/ 10 \mathrm{~min} . / 10^{7}$ organisms. Candida tropicalis grew at about the same rate with a respiration rate of $27.7 \mu \mathrm{l} . \mathrm{O}_{2} / 10 \mathrm{~min} . / 10^{7}$ organisms, i.e. a degradation rate of only $0 \cdot 21 \mu$ mole glucose $/ 10 \mathrm{~min} . / 10^{7}$ organisms. It is thus clear that the growth-limiting factor for organisms when degrading a sugar by aerobic fermentation is not the rate of 
intermediary metabolites synthesis but rather the rate of energy production. Therefore the Crabtree effect must be considered as the repression of an energy-producing system, respiration, by another energy-producing system, fermentation. Thus, when respiration occurs simultaneously with aerobic fermentation, as is the case with the normal strain of $S$. cerevisiae growing on galactose, the compensation that the respiration brings to the deficient rate of fermentation is actually an energy compensation.

\section{Presence of the Crabtree effect in various yeast strains}

The presence or absence of the Crabtree effect in various yeast strains, belonging to various genera (see Table 3) was determined as follows. Fermentation and

Table 3. Presence of the Crabtree effect in various yeast strains

\begin{tabular}{|c|c|c|c|c|}
\hline \multirow[b]{2}{*}{ Organism } & \multicolumn{2}{|c|}{$\begin{array}{c}\mu \mathrm{l} \text {. of gas } / 10^{7} \\
\text { organisms } / 10 \mathrm{~min} .\end{array}$} & \multirow{2}{*}{$\begin{array}{l}\text { Ratio, } \\
\text { fermented } \\
\text { glucose/ } \\
\text { respirated } \\
\text { glucose }\end{array}$} & \multirow[b]{2}{*}{$\begin{array}{c}\text { Crabtree } \\
\text { effect }\end{array}$} \\
\hline & $\begin{array}{l}\text { Respiration } \\
\left(\mathrm{O}_{2} \text { uptake }\right)\end{array}$ & $\begin{array}{c}\text { Aerobic } \\
\text { fermentation } \\
\left(\mathrm{CO}_{2} \text { evolved }\right)\end{array}$ & & \\
\hline aromyces cerevisiae & $4 \cdot 8$ & $78 \cdot 0$ & $49 \cdot 0$ & + \\
\hline evalieri & $1 \cdot 2$ & $90 \cdot 8$ & $250 \cdot 0$ & + \\
\hline gilis & $24 \cdot 5$ & $1 \cdot 9$ & $0 \cdot 23$ & - \\
\hline licus & $0 \cdot 0$ & $94 \cdot 5$ & $\infty$ & + \\
\hline iformis & $0 \cdot 0$ & $61 \cdot 2$ & $\infty$ & + \\
\hline steurianus & $\mathbf{1 . 9}$ & $58 \cdot 7$ & $93 \cdot 0$ & + \\
\hline rbidans & $3 \cdot 6$ & $68 \cdot 2$ & $57 \cdot 0$ & + \\
\hline rlsbergensis & $0 \cdot 0$ & $68 \cdot 2$ & $\infty$ & + \\
\hline osaccharomyces pombe & $0 \cdot 0$ & $40 \cdot 6$ & $\infty$ & + \\
\hline ida utilis & $30 \cdot 0$ & $0 \cdot 0$ & 0.0 & - \\
\hline picalis & $27 \cdot 7$ & 0.9 & $0 \cdot 1$ & - \\
\hline onosa & $21 \cdot 0$ & $0 \cdot 0$ & 0.0 & - \\
\hline osporon fermentans & $15 \cdot 5$ & $0 \cdot 0$ & 0.0 & - \\
\hline enula anomala & $24 \cdot 1$ & $0 \cdot 0$ & 0.0 & - \\
\hline ryomyces globosus & $12 \cdot 3$ & $22 \cdot 2$ & $5 \cdot 4$ & + \\
\hline a fermentans & $24 \cdot 3$ & $1 \cdot 3$ & $0 \cdot 16$ & - \\
\hline anniomyces occidentalis & $9 \cdot 1$ & $0 \cdot 0$ & $0 \cdot 0$ & - \\
\hline anomyces lambicus & $1 \cdot 2$ & $9 \cdot 3$ & $23 \cdot 0$ & + \\
\hline lopsis dattila & $0 \cdot 0$ & $52 \cdot 0$ & $\infty$ & + \\
\hline haerica & $25 \cdot 7$ & $3 \cdot 5$ & $0 \cdot 4$ & - \\
\hline abrata & . & . & . & + \\
\hline lliculosa & $10 \cdot 7$ & $39 \cdot 2$ & $11 \cdot 0$ & + \\
\hline ke & $13 \cdot 3$ & $0 \cdot 0$ & $0 \cdot 0$ & - \\
\hline atospora coryli & $21 \cdot 1$ & $29 \cdot 2$ & $4 \cdot 1$ & + \\
\hline onia fulvescens & . & . & $38 \cdot 0$ & + \\
\hline
\end{tabular}

Note. The absence of a respiration value means that it was too low to be measured in the presence of the high rate of aerobic fermentation.

respiration rates were measured for each strain under the conditions described in Methods. The rate of respiration expressed as $\mu \mathrm{l} . \mathrm{O}_{2}$ uptake $/ 10^{7}$ organisms $/ 10 \mathrm{~min}$. was converted into $\mu$ moles degraded $/ 10^{7}$ organisms $/ 10 \mathrm{~min}$., assuming $1 \mu$ mole glucose degraded $/ 6 \mu$ moles $\mathrm{O}_{2}$ taken up. The same conversion was made for the fermentation rate on the basis of one $\mu$ mole glucose degraded/2 $\mu$ moles $\mathrm{CO}_{2}$ released. The ratio of $\mu$ moles fermented glucose to $\mu$ moles oxidized glucose was taken as a measure of the Crabtree effect. $A$ priori, the Crabtree effect can be considered to be positive when this ratio is $>1$ and negative when the ratio 
is $<1$. The strains tested fell into two classes: (1) those in which the ratio was between infinity and $4 ;(2)$ those in which the ratio was between 0 and $0 \cdot 4$. Class 1 was thus positive $(+)$ and class 2 negative $(-)$ (see Table 3). About $50 \%$ of the strains tested showed no Crabtree effect, although most Saccharomyces strains do show it.

\section{Comparative physiology of the Crabtree effect}

The elaboration of the respiratory system in strains of Saccharomyces cerevisiae appears to be related to low capacity for aerobic fermentation. In view of the priority of fermentation and the suppletive character of respiration in $S$. cerevisiae, it was interesting to compare this organism with Candida tropicalis, which has no Crabtree effect. Table 4 shows that for $S$. cerevisiae the rate of glucose fermentation (in presence and in absence of oxygen) was almost independent of the way the yeast

Table 4. Comparative physiology of the Crabtree effect

\begin{tabular}{|c|c|c|c|c|c|}
\hline \multirow[b]{3}{*}{ Condition of cultivation } & \multirow[b]{3}{*}{$\begin{array}{c}\text { Type of } \\
\text { fermentation }\end{array}$} & \multicolumn{4}{|c|}{ Rate of glucose fermentation } \\
\hline & & \multicolumn{2}{|c|}{$\begin{array}{c}\text { Saccharomyces } \\
\text { cerevisiae }\end{array}$} & \multicolumn{2}{|c|}{ Candida tropicalis } \\
\hline & & $\begin{array}{c}\mu \mathrm{l} . \mathrm{CO}_{2} / 10 \\
\min . / 10^{7} \\
\text { organisms }\end{array}$ & $\begin{array}{c}\text { As } \% \text { of } \\
\text { glucose } \\
\text { value }\end{array}$ & $\begin{array}{c}\mu \mathrm{l} . \mathrm{CO}_{2} / 10 \\
\min . / 10^{7} \\
\text { organisms }\end{array}$ & $\begin{array}{c}\text { As } \% \text { of } \\
\text { glucose } \\
\text { value }\end{array}$ \\
\hline Anaerobic with glucose & Anaerobic & $88 \cdot 7$ & $100 \cdot 0$ & $64 \cdot 7$ & $100 \cdot 0$ \\
\hline Aerobic with glucose & $\begin{array}{l}\text { Anaerobic } \\
\text { Aerobic }\end{array}$ & $\begin{array}{l}81 \cdot 5 \\
78 \cdot 1\end{array}$ & $\begin{array}{l}91 \cdot 9 \\
88 \cdot 1\end{array}$ & $\begin{array}{c}24 \cdot 0^{*} \\
1 \cdot 0\end{array}$ & $\begin{array}{r}37 \cdot 0 \\
1 \cdot 5\end{array}$ \\
\hline Aerobic with lactate & Anaerobic & $22 \cdot 8^{*}$ & $26 \cdot 0$ & $6 \cdot 25 *$ & $9 \cdot 6$ \\
\hline
\end{tabular}

was previously grown, so long as glucose was present during the growth. Figure 1 shows that these fermentation rates remained constant as a function of time (fully induced). For Candida tropicalis the maximum rate of fermentation occurred only after anaerobic growth (Table 4); this rate was of the same order of magnitude as for $S$. cerevisiae, which means that the Crabtree effect was not related to the maximum capacity for fermentation. After growth of C. tropicalis on glucose in aerobic conditions, the rate of anaerobic fermentation was only $37 \%$ of the maximum. Adaptation to anaerobic conditions was quick: after $\mathbf{3 0}$ min. of adaptation, the anaerobic fermentation reached its maximum rate (see Fig. 2). Aerobic fermentation was almost non-existent for $\boldsymbol{C}$. tropicalis, whatever the conditions of cultivation.

More rigorous conditions can be obtained when the strains are compared after growth on a non-fermentable substrate (lactate), and in the absence of glucose. Under these conditions the rate of anaerobic fermentation of glucose was decreased to $25.7 \%$ for Saccharomyces cerevisiae but the adaptation to anaerobic conditions was quick (Fig. 1). For Candida tropicalis the anaerobic fermentation of glucose was decreased to a very low rate $(\mathbf{1 0} \%)$ and the adaptation to anaerobiosis was slow (Fig. 2). These observations are consistent with the opinion that the organisms which exhibit the Crabtree effect show a priority of the fermentation pathway over respiration. The fermentation system is largely constitutive in strains which 
show a Crabtree effect. On the contrary, fermentation is used as an energy plus carbon source only under conditions of anaerobiosis in strains which do not exhibit the Crabtree effect.

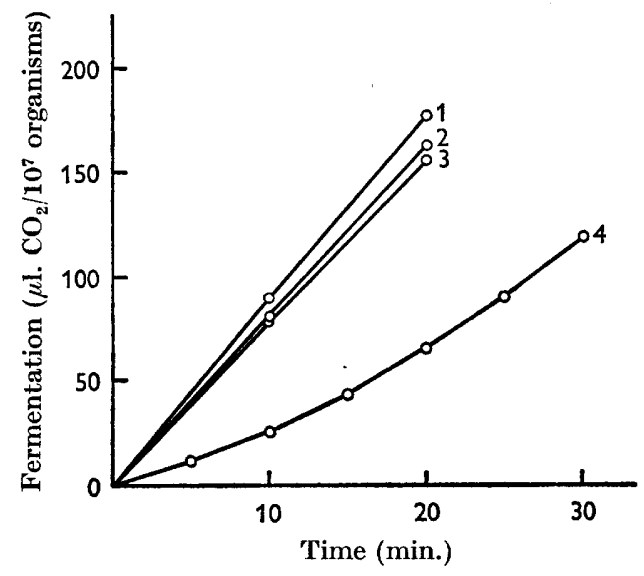

Fig. 1

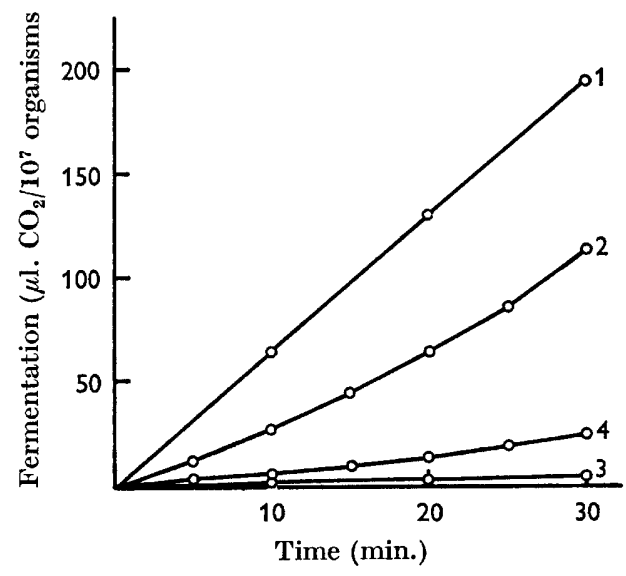

Fig. 2

Fig. 1. Aerobic and anaerobic fermentations of glucose by Saccharomyces cerevisiae after growth on glucose or lactate. Curve 1, anaerobic fermentation after anaerobic growth on glucose; curve 2, anaerobic fermentation after aerobic growth on glucose; curve 3, aerobic fermentation after aerobic growth on glucose; curve 4, anaerobic fermentation after aerobic growth on lactate.

Fig. 2. Aerobic and anaerobic fermentations of glucose by Candida tropicalis after growth on glucose or lactate. Curve 1, anaerobic fermentation after anaerobic growth on glucose; curve 2, anaerobic fermentation after aerobic growth on glucose; curve 3, aerobic fermentation after aerobic growth on glucose; curve 4, anaerobic fermentation after aerobic growth on lactate.

\section{DISCUSSION}

In the presence of air, a normal strain of Saccharomyces cerevisiae is able to grow with glucose, fructose, mannose or galactose as source of carbon plus energy at about the same rate for each substrate. Nevertheless, exponentially growing organisms have rates of aerobic fermentation which decrease from glucose to galactose (five-fold decrease) while the rates of respiration increase from glucose to galactose (four-fold increase). The slow rates of aerobic fermentation of mannose and galactose as compared with glucose might be the result of an inhibition of fermentation by the respiration which occurs simultaneously. In other words, the Pasteur effect might be responsible for the slow fermentation of mannose and galactose. But since we know that the fermentation rates of mannose and galactose are also slow for the petite mutant of $\boldsymbol{S}$. cerevisiae (in which case there is no complication due to respiration) it is clear that the above situation does not result from the Pasteur effect. Thus, the high rate of respiration of galactose results from the low rate of aerobic fermentation of this sugar, and vice versa the very low respiration rate of glucose is the result of the high fermentation rate of this sugar. Now, the slow respiration rate of glucose may result either from an inhibition of the activity or from an inhibition of the synthesis of the respiratory enzymes. Spectroscopic observations made by Ephrussi et al. (1956) showed that aerobic growth of the 
normal strain of $S$. cerevisiae in the presence of high concentrations of glucose resulted in an inhibition of the synthesis of the cytochromes $a, b$ and $c$. The same conclusion is supported by our spectroscopic observations: the normal strain of $S$. cerevisiae growing exponentially on mannose or galactose is much richer in cytochromes than during growth on glucose. In other words, the high respiration rates observed during growth on mannose and galactose are the result of a derepression of cytochromes synthesis.

One can further question whether the repression observed under conditions of high fermentation rates is the result of an accumulation of sugar degradation products or the result of an accumulation of adenosine triphosphate (or other form of energy). The experimental results show that even under conditions of de-repression of the respiratory system, i.e. during growth of the petite mutant on galactose, the rate of fermentative degradation of the sugar was still $0 \cdot 67 \mu$ mole sugar $/ 10^{7}$ organisms/10 min., which is about three times the rate of degradation of glucose via respiration in Candida tropicalis: $\mathbf{0 . 2 1} \mu$ moles glucose $/ 10^{7}$ organisms. $/ 10 \mathrm{~min}$. It was thus not the shortage of intermediary metabolites that allowed a de-repression of the respiratory system when the fermentation rate was slow, but rather the shortage of adenosine triphosphate. This view is consistent with the low energy yield of fermentation as compared with the high energy yield of respiration. It would be useful to have further experimental confirmation; but as far as we know the Crabtree effect appears to be a repression of an energy-producing pathway (respiration) by another such pathway (fermentation).

We wish to thank Dr W. K. Maas and Dr E. McFall for help in preparing this article.

\section{REFERENCES}

Crabtree, H. G. (1929). Observations on the carbohydrate metabolism of tumors. Biochem. J. 23, 536.

Ephrussi, B., Slonimski, P. P., Yotsuyanagi, Y. \& Tavlitzki, J. (1956). Variations physiologiques et cytologiques de la levure au cours du cycle de la croissance aérobie. C.r. Lab. Carlsberg, ser. physiol. $26,87$.

Lemoigne, M., Aubert, J. P. \& Millet, J. (1954). La production d'alcool et le rendement de croissance de la levure de boulangerie cultivée en aérobiose. Ann. Inst. Pasteur, 87, 427.

Salas, M. L., Viñulla, E., Salas, M. \& Sols, A. (1965). Citrate inhibition of phosphofructokinase and the Pasteur effect. Biochem. Biophys. Res. Comm. 19, 371.

Slonimski, P. P. (1956). Adaptation respiratoire: développement du système hémoprotéique induit par l'oxygène. Proc. 3rd int. Congr. Biochem. p. 242.

Swanson, W. H. \& Clifton, C. E. (1948). Growth and assimilation in cultures of Saccharomyces cerevisiae. J. Bact. 56, 115. 